\title{
STUDIES ON THE DEVELOPMENT OF WHITE CLOVER SEED
}

\author{
By E. 0. C. Hyde
}

Senior Seed Research Officer, Plant Chemistry Laboratory, Department of Scientific and Industrial Research,

Palmerston North.

The papers that follow in this symposium will deal with various aspects of the behaviour of clover plants, but mainly with the reactions of seed and seedlings to environmental conditions. It is reasonable therefore at the outset to consider the nature of the clover seed and the ways in which the properties of the seed may vary.

We are getting a better understanding of the characteristics of the seed of pasture plants through the study of seed development. I propose therefore to give an outline of the development of white clover seed and show how this throws light on several aspects of seed quality. Special attention will be given to the effect of maturity on seedling vigour and the effect of humidity conditions at the ripening stage upon hard seeds.

The method used to study the process of seed development was as follows:-

Large numbers of flowers were tagged and then at intervals of two days samples of the tagged seed heads were collected. In this way seeds of known age were obtained. Some of these seeds were used to determine the average weight and water content. The remainder was dried and kept for germination studies.

Before considering the- results I want to explain what meaning has been attached to the terms "maturity" and "ripeness." Seed is "mature" when it has acquired its maximum dry weight. Seed is spoken of as "ripe" when it has dried out to a moisture content in equilibrium with the atmosphere.

It should also be exnlained that the picture obtained of the course of development of the seed has been built up from measurements which give the average condition of samples. There is, of course, an inherent variability in the material, and so it is reason- 
able to assume that the changes occurring in the course of development of an individual seed may occur rather more rapidly than is indicated in our diagrams.

\section{STAGES IN SEED DEVELOPMENT}

The development of, a white clover seed from pollination to ripeness. occupies about 26 days. It appears that this period may be reduced or extended by approximately 5 days in accordance with weather conditions.

Three stages can be recognised in the development to the seed:

1. The growth stage.

2. The stage of food reserve accumulation.

3. The ripening stage.

The first 'stage occupies a period of 10 days following pollination. During most of this time the growth rate of the ovule is logarithmic and is presumably determined by the rate of cell division in the embryo and seed coat. Throughout this first period the. moisture content of the seed is constant at approximately 79 per cent. of the fresh weight,

The second stage takes up the period from the 11 th to the 21 st day. The rate of growth during this period is nearly uniform and is presumably determined by the rate at which food reserve material can be transferred from the plant to the seed. During this period the dry matter in the seed increases about threefold. The actual amount of water in the seed declines slightly, but the water content as a percentage of the fresh weight falls from 79 per cent. to about 63 per cent.

The third or ripening stage lasts from the 21st to the 25th day. During this period the seed dries out rapidly and shrinks in size. There is no appreciable change in dry weight, but the fresh weight falls to less than half as the moisture content declines from 63 per cent. to 10 per cent.

It is probable that the drying out of individual seeds is often more rapid than has been indicated and may be completed in one or two days.

\section{THE EFFECT OF MATURITY ON SEED QUALITY}

Under natural conditions seed development proceeds to completion before the seed falls to the ground. But when seed is harvested much of it is cut and ripened prematurely. Generally at the time of cutting, 
while much of the seed is already ripe, some heads are blooming and every intermediate stage of development is also represented. So the question arises: how is the quality of the seed affected by the stage of development of the seed at the time of harvesting?

The aspects of quality that interest us most are:

1. Viability.

2. Seedling vigour.

3. Storage life.

\section{VIABILITY}

We shall first consider viability, i.e., the capacity of the seed to resume growth after having been dried. Viable seed was first obtained on the 10th day after flowering, and by the 15 th day 90 per cent. of the seeds were viable. It appears that the seed becomes viable soon after the first stage of development is completed, when the dry weight of the seed is only about one third to a half of that of the mature seed.

\section{SEEDLING VIGOUR}

It is not sufficient that seed should germinate. We are also concerned to know whether it will produce " vigorous seedlings. The property of vigour is not easy to measure. It is reflected in speed of germination, size of seedling, rate of seedling growth, and the depth of soil through which the seedling can emerge.

When samples of seed harvested at different stages of development were scarified and placed to germinate it was found that the speed of germination increased with advancing age at harvest. However, the differences in speed were small. The time required for 90 per cent. of the viable seeds to germinate at 55 degrees F. was approximately three and a half days for seed harvested 12 days after flowering and 2 days for mature seed.

A comparison of the size of seedlings grown from mature and immature seeds throws more light on the question of vigour. Seedlings from seed harvested at the 12 day stage, after growing for 6 weeks in a glasshouse, had approximately half the fresh weight of seedlings from mature seed. The weight of the seedlings was found to be directly proportional to the initial seed weight. There was no evidence that seedlings from immature seed, when once established, suffered any handicap apart from that initial smallness.

\footnotetext{
103
} 
A critical stage in the life of a seedling is the period from sprouting to emergence, and at this stage seedlings from immature seeds may be handicapped by deficient food reserves. Immature seed gave a lower percentage rate of emergence when deeply sown than did mature seed. When sown in sand at 68 degrees F. to a depth of 1.6in. the rate of emergence with seeds 14 days old at harvest was nil ; with mature seed it was 40 per cent.

\section{STORAGE LIFE}

Another important aspect of quality in seeds is the ability to retain germination capacity during storage. What effect has maturity on this property? To throw light on this point, samples of white clover seed harvested at different stages of maturity were stored at a temperature of 99 degrees $\mathrm{F}$. and at 70 per cent. relative humidity. These conditions are much more adverse than those normally encountered in a seed store. They were used.in order to accelerate the degenerative process which takes place in stored seeds.

After one month under these conditions all samples had begun to decline in germinating capacity. The rate of decline was most rapid in the extremely immature seed, and was progressively slower with samples of increasing age at harvest.

From all points of view mature clover seed proved to be better than immature seed. This, of course, is not surprising. But it is of some interest to see in what manner and in what degree immaturity affects seed quality.

Normal seed cleaning removes all seeds that are too immature to germinate and also much light, immature seed which is nevertheless viable. Notwithstanding this, it would appear that immaturity is one of the main factors reducing the quality of. commercial seed.

The most satisfactory indicator of maturity is seed weight. In some European countries one of the main criteria of quality in agricultural seeds is the weight of 1000 seeds taken at random from a sample of the stock. We in this country might do well to use some such measure in judging seed quality. 
Field practices which ensure the harvesting of a greater proportion of a seed crop in the mature condition are worth encouraging. Reports on suction harvesters in use overseas indicate that they may improve the efficiency of harvesting mature seed of pasture plants.

\section{HARD SEED}

We cannot consider the germination of clover seed without taking into account the "hard seed" condition, that is, the condition of the seed coat of ripe seed which obstructs the uptake of water and delays germination. Hard seeds first appeared in samples collected on the 12th day after flowering. The proportion of hard seeds increased with advancing age at harvest, until on the 25th day 96 per cent. of the viable seeds were hard.

It is apparent that nearly all the clover seeds which ripen in the normal manner on the plant are in the dormant hard seed condition. And these are the seeds which are effective in the natural regeneration and spread of clovers.

The condition of commercial clover seed which is artificially harvested is very different. Much of the harvested seed is cut and ripened before it is fully mature and all of it is subjected to rubbing and scarifying in the processes of threshing and cleaning. This mechanical treatment scratches or cracks the seed coat and renders the hard seeds capable of taking up water promptly and germinating without delay when sown.

Reference has been made to the delayed germination of clover seeds in the dormant hard seed condition. The questions naturally arise: What is the length of this delay ; are there varying degrees of hardness, and what conditions induce the hard seeds ultimately to germinate?

Overseas workers have shown that extremes of heat and cold will break down the hard seed condition, but as far as we have been able to ascertain the temperature extremes in our climate do not bring about marked seasonal changes in the rate of germination of dormant clover seeds.

The duration of the delay in germination appears to depend mainly on conditions within the seed and to be determined by the intensity of drying during 
the ripening period. In one experiment mature but unripened seeds were taken from a crop of pedigree white clover and divided into five lots each of which was ripened at a different level of relative humidity. The ripened seed was then tested for germination at 68 degrees F., the tests being prolonged for 18 months.

Relative humidity within the range of 70 per cent. to" 30 per cent. did not have a significant effect on the percentage of hard seeds, but it did have a great effect on the duration of the hard seed condition. The drier the atmosphere in which the seeds were ripened the longer the delay in germinating. Seeds ripened at a relative humidity of 70 per cent. all germinated within 5 months. Seed ripened at 30 per cent. relative humidity has shown only 3 per cent. germination in 18 months.

It is reasonable to assume -that clover seeds which ripen in humid weather or beneath dense foliage are likely to germinate within the following year, whereas seeds ripening in dry, open conditions may remain dormant for several years.

\section{CONCLUSION}

In conclusion there are a few points which I should like to stress, because they are relevant to the subjects discussed in the "papers that follow:-

1. The interval between the flowering of white clover and the ripening of the seed is 3 to 4 weeks.

2. White clover seed becomes viable 12 to 14 days after flowering.

3. Seed size, speed of *germination, seedling vigour, and storage life all improve as development progresses up to the stage of full maturity.

4. About 95 per cent. of white clover seeds that ripen under natural conditions are in the dormant hard seed condition.

5. The speed of germination of the hard seeds is influenced greatly by humidity conditions during the ripening stage. According to the intensity of drying, the delay in germination may be a few months or several years.

106 
Effect of Adverse Storage Conditions on the Germinating Capacity of White Clover Seed of Different Ages at Harvest.

\begin{tabular}{|c|c|c|c|}
\hline $\begin{array}{l}\text { Age of seed at } \\
\text { harvest in days }\end{array}$ & $\begin{array}{l}\text { Initial Ger- } \\
\text { mination } \\
\text { per cent. }\end{array}$ & $\begin{array}{l}\text { Germination } \\
\text { per cent. after } \\
\text { storage for } 1 \\
\text { month at } 99 \circ \\
\text { F. arud } 70 \% \\
\text { rel. humidity }\end{array}$ & $\begin{array}{l}\text { Loss of } \\
\text { germinating } \\
\text { capacity as a } \\
\text { percentage of } \\
\text { initial capacity }\end{array}$ \\
\hline 13 & 84 & 5 & 94 \\
\hline 14 & 92 & 8 & 91 \\
\hline 17 & 91 & 33 & 64 \\
\hline 19 & 96 & 52 & 46 \\
\hline 24 & 93 & 79 & 15 \\
\hline
\end{tabular}

Percentage Rate of Seedling Emergence. Effects of Seed Age at Harvest and Depth of Sowing.

\begin{tabular}{crrrrr}
\hline $\begin{array}{c}\text { Depth of Sowing } \\
\text { inches. }\end{array}$ & \multicolumn{5}{c}{$\begin{array}{c}\text { Age of Seed at Harvest in days } \\
\end{array}$} \\
\hline & 12 & 14 & 17 & 19 & 24 \\
.2 & 87 & 92 & 97 & 97 & 93 \\
.4 & 81 & 82 & & 94 & \\
.8 & 62 & 74 & 94 & 94 & 9690 \\
1.6 & 0 & 0 & 16 & 30 & 37 \\
\hline
\end{tabular}

